\title{
Digital preservation of language, cultural knowledge and traditions of the indigenous Semai
}

\author{
Sumathi Renganathan ${ }^{1, *}$ and Inge $\mathrm{Kral}^{2}$ \\ ${ }^{1}$ Universiti Teknologi PETRONAS, Malaysia \\ ${ }^{2}$ Australian National University, Australia
}

\begin{abstract}
In this paper we describe two community-based participatory research projects in an Orang Asli community that set out to document their local knowledge and culture. We describe how with the support of technology we are able to document indigenous oral traditions and practices that are on the verge of disappearing. The Semai are the largest Orang Asli community in Peninsular Malaysia and mainly live in the states of Perak and Pahang. Like in many other indigenous contexts, the Semai peoples' transition from an oral culture to a literate culture is relatively recent. In this paper we discuss how our long-term relationship has facilitated two projects using digital media technology that focus on the documentation of local knowledge and culture of the community members in a Semai-speaking village in Perak. Elders in this community, having local knowledge accumulated over generations through direct experiences and participation, were the main source of information for these documentation projects, while younger people assisted with film and audio recording, editing, as well as language transcription and translation. The elders in this Semai community recognise the value and importance of transmitting their local culture and knowledge to the next generation. The projects described in this paper led to the production of two short films in 2014 , and a book project, which began in early 2017, is currently underway. Thus, this paper highlights how technology is an enabler in the preservation of endangered indigenous knowledge and culture.
\end{abstract}

\section{Introduction}

According to Ethnologue (Simons et al., 2017), the most extensive catalogue of the world's languages, there about 7000 distinct languages in the world. However, by the end of this century it is predicted that about half of this world's languages will be extinct as it is estimated that one language dies every two weeks (Kraus, 1992; Aulakh, 2013). Languages becoming extinct is not recent phenomenon, in fact every region in the world is vulnerable to this.

The UNESCO Atlas of the World's Languages in Danger (2011) cites that there are approximately 3000 endangered languages across the globe and those most at risk of extinction are Indigenous languages (UNESCO 2003). The loss of endangered minority indigenous languages represents a profound loss to humanity at a global level.

Local and indigenous knowledge refers to the understandings, skills and philosophies developed by societies with long histories of interaction with their natural surroundings. For rural and indigenous peoples, local knowledge informs decision-making about fundamental aspects of day-to-day life. This knowledge is integral to a cultural complex that also encompasses language, systems of classification, resource use practices, social interactions, ritual and spirituality (UNESCO, 2018).

Language is the medium linking people to knowledge and therefore, a community's connection with its history, its culture and tradition and its base of specific knowledge are lost when a particular language has ceased

\footnotetext{
*Corresponding author: sumathi@utp.edu.my
} 
to exist anymore. "The wisdom of humanity is coded in language," and thus when a language dies, the knowledge disappears with it (Campbell, L. cited in Wallace, 2010). Indigenous cultural knowledge refers to traditional practices and knowledge of the ways of life of that particular indigenous community which are passed down generation to generation that forms part of their unique identity and heritage.

For many indigenous minority communities everywhere, the threat of their language becoming extinct is very real. As indigenous communities come from a non-literate tradition, their knowledge and culture are passed from one generation to another orally. In addition, oral narratives not only pass on these forms of knowledge, but also the social values and the collective memory of that community. Thus when a language of a community is lost, traditional knowledge of the community is also lost. There are many reasons why a language becomes endangered or even extinct. In Malaysia, for minority communities such as the indigenous Orang Asli, learning and speaking the majority languages such as Malay and English are seen as economically advantages. These are the languages of education and it is perceived that mastering them will give speakers access to better jobs and successful futures. On the other hand, indigenous Orang Asli languages are perceived to be less prestigious and usually seen as useful only for personal uses at home or between indigenous community members. Thus, negative perception and low status are some of the major underlying causes for indigenous languages becoming endangered. According to Karim (2001), in Malaysia, many indigenous Orang Asli languages and cultural traditions face extinction, largely because many of these languages are not documented (Benjamin, 1976, 2012). Documentation is often regarded as extremely important for the continued survival of indigenous minorities' cultural heritage.

\section{The Semai}

We now turn to the projects focusing on one indigenous Orang Asli community, the Semai. These projects set out to document the language, cultural knowledge and traditions of the Semai speakers from a small village in Perak. The Semai indigenous people are mainly found in the states of Pahang and Perak in Peninsular Malaysia. A community that once depended on hunting and swidden farming, at present are mainly laborers in factories and oil palm and rubber plantation; or work for daily wages from available low-paid odd jobs.

Semai is a Mon-Khmer language belonging to the Aslian family of languages. Aslian languages are spoken in areas of Peninsular Malaysia and the southernmost part of Thailand. According to the Atlas of the World's endangered languages, Semai is categorised as severely endangered (Moseley, 2010; Theguardian, 2017) and is only spoken by about 15000 people. A language that is severely endangered implies that the language is spoken by the older generation including grandparents; while the parent generation although may understand the language, they do not speak to children or among themselves.

For a non-literate indigenous community like the Semai, languages live in stories, songs, and traditional cultural practices and like other intangible cultural heritage, oral narratives are threatened when modernization and environmental changes take place. Sometimes literate resources and practices such as books, magazines, radio, television and internet have had a damaging effect on oral traditions. Therefore, the digital documentation projects that we present in this paper are crucial in providing a record of Semai history, culture and traditions should they be lost if the Semai language itself is no longer spoken by the Semai community.

\section{The Documentation Projects: Towards a digital preservation of Semai Heritage}

One of the major difficulties working on documentation projects is having access to indigenous communities. In addition, for projects where the documentation of indigenous community cultural practices is central, a level of trust and accountability must exist between researchers and community members. This is one of the main reasons why community projects such as this are not only limited but are also difficult to carry out. However, the authors of this paper have worked closely with this particular Semai village since 2008 (Renganathan \& Chong, 2009, 2010; Renganathan, 2016; Renganathan \& Kral, 2017). Furthermore, in both the documentation projects we describe and discuss in this paper, we worked very closely with the indigenous village community members especially the Tok Batin (Village Headman). Both projects adopted an ethnographic approach and mainly utilised 
in-depth interviews and participant observations. In addition, both projects discussed in this paper focused on the concept of 'language as cultural practice' (Nicholas 2014; Schecter \& Bayley 2002).

\subsection{Project 1- Documenting the Semai cultural traditions}

This project took place in the year 2014. The outcome of this project was 2 short one-hour films where the use of digital technologies and the film-making medium not only supported the documentation project but also initiated an intense interest in Semai language and culture especially among the youth in this village. This project took about 2 weeks of rigorous fieldwork in the Semai village working together with a specific team of Semai youth and other community members. The young people involved were volunteers who answered the Tok Batin's call to be part of this project. They consisted of four young women aged between 16-26 and one 16-year old adolescent male.

The content for the films was decided by the Tok-batin and the youth team members. They brainstormed and decided among themselves what, how and where the content for this project should be filmed. The young people were given two Kodak Playsport HD video cameras (similar to the size of a hand phone) to film whatever they themselves identified as important whereas the other aspects of the filming was directed by the Tok Batin and filmed by the second author using a professional video camera. This consisted of a professional quality Sony HXR-NX70P DV camera with wireless lapel microphone.

Once all filming was completed, the editing part of the project began. This was handled by two specific members from the Semai Youth team, Erna, a mother of two who was about 22 years old at the time this project was undertaken and Roomrid, a 16-year old school dropout who had completed 3 years of secondary school and was waiting at that time to start work in a nearby restaurant at washing dishes. The Tok Batin also assisted, especially in providing the necessary cultural authority and language input whenever needed. The editing took place in the village Community Centre where we used two computers, a Mac Book Pro and a PC laptop. We used the PC for the compilation of text documents, while the film was edited using Final Cut Pro (FCP) software on the Macbook. The young male, Roomrid, acquired the skills to independently edit the film after an initial demonstration on how to use the FCP software and minimal support. As the Semai are from a non-literate tradition, Roomrid was a natural visual learner who quickly remembered and mastered the sequence of actions demonstrated to him by the editing mentor by focusing on the visual codes. Later Roomrid taught Erna how to edit, by using similar aural cues he had learned from earlier. As both these young people were the ones who were familiar with the content, they became the experts in sequencing and editing the films and the narrative accompanying the visuals. This project demonstrated how technology enabled youth from a non-literate tradition to become confident in exploring and gaining competence in using complex technical editing functions. These actions not only empowered them, but also gave them control of telling their own stories as they were in charge of the oral, written text and the visual narrative of the films.

The digital documentation project enabled the young adults to participate in a meaningful role in their cultural traditional practices in a modern way and placed them in a crucial position as 'knowledge holders and conduit of cultural information for the next generation' (Kral \& Renganathan, 2018, p.379). The two short films: May Serak Temboh Bekeet: Tradisi May Sengooy Semai (The traditions of the Semai) and Ki Cerita Tentang Sinuy May Sengooy Semai (Stories of the Semai) have now been archived at the Pacific and Regional Archive for Digital Sources in Endangered Culture (PARADISEC). Hence this data will now be accessible for future generations. Work is also underway to provide suitable bilingual subtitles in Semai and Malay, and is expected to be completed by end of 2018. A detailed account of this project is presented as a chapter in an edited volume published in 2018 (Kral \& Renganathan, 2018).

\subsection{Project 2 - Production of an edited volume on language, culture and history of the Semai}

This second project again involved collaborative work with the Semai villagers and began in early 2017. This project involved the digital recording of a collection of stills and audio visual materials on the oral traditions, history and cultural practices of the Semai elders. The idea for this project was first conceptualized by the Tok Batin and a few elders living in the village. The project involved about 30 people from the village, including young people and their elders 
The core collection of the data for this project includes:

- Three hours of video recordings of 17 Semai elders demonstrating cultural practices and traditions;

- 420 digital stills of cultural materials and traditional artefacts;

- $\quad$ Four hours of audio recordings of life story narratives from some 20 community members.

At present, translation from Semai to colloquial Malay has already been completed by a Semai research assistant. We are now working on the translation from colloquial Malay to Standard Malay and then to English. The edited volume will showcase all three languages. We have also been working on matching the collection of digital stills with appropriate narrated context obtained from the Semai elders. The drafting of chapters using this material is well underway.

The outcome of this work will enhance language revitalization, acquisition and use among the Semai and develop pride in their oral and cultural traditions. The completion of the edited volume will also enable the public to acknowledge and appreciate Semai language, culture and traditions.

\section{Conclusion}

Digital technology has provided opportunities for language and cultural maintenance and transmission for indigenous communities such as the Semai who are experiencing language and culture shift or loss. Thus, projects such as the ones highlighted in this paper show how the sustainability of indigenous traditional cultural knowledge is made possible with the help of modern technology. Both the projects presented in this paper highlight how through participation in meaningful community-based digital projects, non-literate communities such as the Semai are able to actively engage in projects that assist in the maintenance of their language and traditional cultural practices.

\section{References}

Aulakh, R. 2013. The Star.com. Dying languages: scientists fret as one disappears every 14 days. Retrieved from https://www.thestar.com/news/world/2013/04/15/dying_languages scientists_fret_as_one_disappears_every_14_days.html. Accessed on $5^{\text {th }}$ June 2017.

Benjamin, G. (1976). Austroasiatic Sub-groupings and Prehistory in the Malay Peninsula. In P. N. Jenner, L.C. Thompson and S. Starosta, (Eds), Astroasiatic Studies (pp. 37-128). Hawaii: The University Press of Hawaii.

Benjamin, G. (2012). The Aslian languages of Malaysia and Thailand: An assessment. In Peter K. Austin \& Stuart McGill (eds). Language Documentation and Description, 11, 136-230.

Karim, W. J. (2001). Minorities of the minority: Language death and patterns of cultural extinction. In Razha Rashid and Wazir Jahan Karim (Eds), Minority cultures of Peninsular Malaysia: Survivals of Indigenous Heritage (pp. 69 -74). Penang: Academy of Social Science (AKASS).

Kral I. \& Renganathan S. (2018) Beyond School: Digital Cultural Practice as a Catalyst for Language and Literacy. In Wigglesworth G., Simpson J., Vaughan J. (Eds), Language Practices of Indigenous Children and Youth: The transition from home to school (pp. 365-386). London: Palgrave Studies in Minority Languages and Communities. Palgrave Macmillan.

Krauss, M. (1992). The world's languages in crisis. Language 68, 4-10.

Moseley, Christopher (Ed.). (2010). Atlas of the World's Languages in Danger, 3rd Edition. Paris, UNESCO Publishing. Online version: http://www.unesco.org/culture/en/endangeredlanguages/atlas 
Nicholas, S. E. (2014). "How are you Hopi if you can't speak it? An ethnographic study of language as cultural practice among contemporary Hopi youth. In T.L. McCarty (Ed.), Ethnography and language policy (pp. 5375). New York/ London: Routledge.

Renganathan, S. (2016). Educating the Orang Asli children: Exploring indigenous children's practices and experiences in schools. The Journal of Educational Research, 109(3), 275-285.

Renganathan, S. and Chong, S. L. (2009). Disparity in School's Literacy Practices and that of Home: Understanding Orang Asli Children's Educational Needs in Malaysia. Singapore: Paper published in the proceedings of the 2009 International Conference on Social Sciences and Humanities, ICSSH.

Renganathan, S. and Chong, S. L. (2010). Exploring Multiliteracies and Social Practices of the Orang Asli Children in Perak. Report submitted to the Educational Planning and Research Division, Ministry of Education

Renganathan, S. and Kral, I. (2017) Using Media as a catalyst for literacy, and language and culture maintenance, in an Orang Asli village in Peninsular Malaysia. Research talk presented in UPM, Malaysia

Simons, Gary F. and Charles D. Fennig (Eds.). (2017). Ethnologue: Languages of the World, Twentieth edition. Dallas, Texas: SIL International. Online version: http://www.ethnologue.com.

Schecter, S. R. and Bayley, R. (2002). Language as cultural practice: Mexicanos en el Norte. Mahwah: Lawrence Erlbaum Associates.

Theguardian. (2017). Endangered languages: the full list. From https://www.theguardian.com/news/datablog /2011/apr/15/language-extinct-endangered. Accessed on $5^{\text {th }}$ June 2017.

UNESCO. (2018). Local and Indigenous knowledge system cited from http://www.unesco.org/new/en/naturalsciences/priority-areas/links/related-information/what-is-local-and-indigenous-knowledge/

UNESCO (2011). Atlas of the World's Languages in Danger. Paris: UNESCO.

UNESCO (2003). Language Vitality and Endangerment. UNESCO Ad Hoc Expert Group on Endangered Languages. Document submitted to the International Expert Meeting on UNESCO Programme Safeguarding of Endangered Languages. Paris, 10-12 March 2003.

Wallace, Lane (2010). What's Lost When A Language Dies The Atlantic. https://www.theatlantic.com/national /archive/2009/11/whats-lost-when-a-language-dies/29886/. Accessed 6 June 2017 